\title{
Sig y Paleohidrología: Reconstrucción del modelo hidrológico en el yacimiento paleolítico del Camino de Salmedina
}

\author{
Carmen Conde* \\ Javier Baena Preysler* \\ * Dep. Prehistoria y Arqueología. Universidad Autónoma de Madrid 28049
}

\begin{abstract}
Resumen
La abundancia de testimonios paleolíticos en la región sur de Madrid, ha sido una constante dentro de las investigacione sobre el Pleistoceno de la zona. La ausencia durante mucho tiempo de una adecuada política de excavaciones y sondeos que permitieran contextualizar estos conjuntos, obliga en ocasiones a recurrir a procedimientos imaginativos a la hora de comprender la génesis de este tipo de depósitos superficiales. En este trabajo, mediante el empleo de SIG realizamos un ensayo de aplicación para el conjunto Paleolitico Medio del Camino de Samedina, estableciendo más que probables relaciones entre los depósitos industriales y posibles paleocauces en la zona.
\end{abstract}

Plabras clave: SIG, Pleistoceno, Paleolítico, prospección

\section{Abstract}

The abundance of paleolíthic testimonies in the South region of Madrid, has been a constant within the Pleistocene research of the Zone. Sometimes the absence during long suitable time of political of excavations and soundings that allowed to understand the origin of these sets, forces to resort to imaginative procedures at the time of including/understanding the genesis of this type of superficial deposits. In this work, by means of the GIS use, we made a test of application for the Camino de Salmedina Middle Paleolithic site, establishing more than probable relations between the possible industrial deposits and old streams in the zone.

Key words: GIS, Pleistocene, Palaeolithic, survey

\section{INTRODUCCIÓN}

Desde hace más de un siglo, es conocida la riqueza paleolítica de la región madrileña merced a una tan extensa como antigua bibliografía (Baena et al. 2002). El desarrollo de la investigación en este campo dentro de nuestra región, ha sido sin embargo muy poco continuo y se ha caracterizado por continuas aceleraciones y desaceleraciones, siguiendo en muchos casos el estado anímico de los propios investigadores. En la actualidad, disfrutamos de un momento álgido en el que proliferan numerosas iniciativas y actuaciones de campo, sin que por el momento ello se plasme en la bibliografía, con la publicación de nuevos yacimientos.

El estudio del yacimiento del Camino de
Salmedina es una pieza más del enorme rompecabezas que forman un sin fin de conjuntos, cuyo estudio puede no aportar, desde un punto de vista antropológico o tecnológico, información trascendente en el desarrollo histórico humano, pero que sin embargo, requiere como todo testimonio arqueológico, de la justa y necesaria atención.

\section{LA PROBLEMÁTICA DE LOS YACIMIENTOS PALEOLÍTICOS EN SUPERFICIE: INTERPRETA- CIÓN Y TIPOS}

La mayoría de los yacimientos en superficie han sido objeto de limitada atención por parte de los investigadores, dado su escaso atractivo para el estudio, la elevada alteración y las limitaciones interpretativas (Vega Toscano, 1988). 
Este tipo de yacimientos pueden presentarse concentrados, pero generalmente aparecen muy dispersos y con dificultades a la hora de establecer sus límites. La mayoría de ellos pueden considerarse palimpsestos, donde la actividad humana ha actuado durante periodos de tiempo prolongados.

Por esta razón, es difícil en la actualidad que estos yacimientos de grandes extensiones y sin límite preciso tengan una correcta interpretación. Lo que esta claro es que aún siendo muy frecuentes en toda la geografía peninsular, siempre son objeto de escaso interés de cara a su publicación. Ciertamente, la desestimación de estos conjuntos, muchas veces recogidos por aficionados y sin la contextualización necesaria, supone una pérdida de información que aún a pesar de su limitada relevancia, no debemos asumir (Vega Toscano, 1983).

También es cierto que existe en este tipo de conjuntos, un claro carácter diacrónico; donde podemos dudar de la validez de sus aportaciones científicas. Sin embargo, creemos que es necesario destacar su presencia, con el fin de no dejar lagunas en la distribución espacial de las evidencias. Suele apreciarse en ellos diferencias temporales acusadas en lo que se refiere a la industria lítica, circunstancia en la que interviene notablemente la dinámica sedimentaria y los ciclos erosivos (Santonja, 1992).

Ahora bien, si lo que pretendemos es analizar estos conjuntos, habrá que comenzar por efectuar sobre este tipo de testimonios un análisis coherente sobre el conjunto, su contexto así como los factores que han intervenido en su distribución tal y como aparece hoy en día. En los yacimientos en superficie, es frecuente la presencia de distinto grado de rodamiento y pátina en los materiales. Esta circunstancia se explica, por la propia dinámica de los medios fluviales, en muchos casos desaparecidos en la actualidad, o bien por la escorrentía superficial o el viento, que actuarían de forma diferencial sobre las piezas. Por ello resulta necesario constatar si los conjuntos industriales en estudio han estado siempre en superficie, o por el contrario han pertenecido a algún tipo de depósito, con anterioridad a su transporte y redepósito sobre el emplazamiento definitivo.

Si a lo anteriormente expuesto le unimos la posibilidad (muy frecuente) de que procesos semejantes estuviesen separados en el tiempo, como resultado obtendríamos una acumulación de industrias de épocas distintas, mezcladas y alteradas en un mismo proceso, que, con un aspecto externo parecido, dificultan la interpretación del estudio de materiales.

Tampoco en contextos europeos se ha tenido excesivamente en cuenta este tipo de yacimientos, que durante bastante tiempo han sido tratados como la "cenicienta" de la Arqueología paleolítica. La dificultad de su estudio es evidente, con la intervención de fenómenos diversos muy espaciados en el tiempo en los que existe una limitada garantía de coherencia cultural. En el estudio realizado en el yacimiento en superficie en los alrededores del río Mosa, (Alemania), se analizaron diferentes áreas del fondo del valle, buscando una homogeneidad en la tecnología y una respuesta geomorfológica al terreno. Según los autores, los grupos humanos captaban el sílex de sus afloramientos en el fondo del valle, donde iniciaban el proceso de talla, preparando núcleos y realizando algunos útiles, que después serían transportados a la zona de actividad principal. Una vez finalizada la tarea se trasladarían con el utillaje a otra zona, donde supuestamente reutilizarían las piezas talladas anteriormente (Kolen et.al.; 1999).

Esta hipótesis propone la existencia de un "nicho tecnológico" donde cada espacio presenta una sección específica de la cadena operativa. La mayoría de los yacimientos se encuentran situados cerca de afloramientos de materia prima, presentando porciones interrumpidas de la cadena operativa.

En los espacios de captación aparecen por tanto lascas con retoque, pero no útiles completos (como en el caso de Camino de Salmedina). Muchos de ellos pueden haber sido causados como consecuencia del frision effect (proceso de fricción que produce estos retoques, o por la reutilización de las lascas) (Diez Martín, 2000). Ambos espacios, fondos de valle y zonas elevadas, ofrecen condiciones distintas pero en cualquier caso favorables, para el asentamiento de las comunidades primitivas. La visibilidad sería un factor muy atractivo, ya que desde ese punto se percibirían los movimientos de las manadas animales, al igual que los restos abandonados por los carnívoros, carcasas fácilmente aprovechables.

Sobre el estudio ejemplar de este yacimiento en superficie, las posibilidades de tratamiento analítico de estos conjuntos resultan más esperanzadoras. El Paleolítico Medio en superficie presenta un alto potencial informativo, a veces único, sobre el comportamiento de los grupos y su utilización específica del espacio, en lo que respecta a los patrones de captación de materia prima (Kolen et.al.; 1999). 


\section{AnÁlisis de los CONJUNTOS SUPERFICIALES.}

Contamos con dos problemas a la hora de analizar los conjuntos superficiales. Uno de los principales es la contextualización cultural de las series, como consecuencia de la falta de datos estratigráficos. La correcta adscripción cronológica de estos conjuntos debe pasar necesariamente por el análisis de la génesis de los depósitos. Esta labor, que no garantizará en la mayor parte de los casos una cronología ajustada, con frecuencia sí permite aproximar una fecha post quem (Martín Blanco, P., et al. 1994).

Igualmente, para obtener un resultado valido debemos de partir de un análisis detenido del grado de representatividad de la muestra (excluyendo los conjuntos con número de piezas no significativo) y de la procedencia de la serie (Santonja, 1992).

El estudio pasa por realizar un análisis de:

- El origen, casi siempre dinámico, con intervención de transporte hídrico, al igual que los movimientos del terreno, procesos erosivos, $\mathrm{y}$ dinámicas de sedimentación complejas.

- La delimitación del yacimiento que resulta así mismo imprescindible, además muchas veces presenta límites difusos (como es el caso del yacimiento de Camino de Salmedina). Si existe una importante concentración de material lítico y no se percibe una ruptura de continuidad en la dispersión, probablemente la asociación industrial es el resultado de múltiples acciones geológicas, lo que implica procedencias diferentes. Esto sitúa al investigador, de nuevo, en el punto de partida (Martín Blanco, P., et al. 1994).

- Una vez realizado el estudio geomorfológico, el análisis tecnológico de la industria, y la búsqueda de cadenas operativas que nos aclare su presencia y representatividad será un paso imprescindible en la determinación de la homogeneidad y coherencia del conjunto (Geneste 1988, 1991). Una vez establecida la delimitación y la concentración de material lítico, se realiza el estudio de la cadena operativa, sobre una la muestra mínima de 100 piezas sobre la que poder evaluar el origen y la naturaleza del conjunto (Santonja, 1992).

Todos estos criterios podrán determinar la homogeneidad o la heterogeneidad de la muestra. Igualmente, uno de los factores a tener en cuenta pasaría por definir la funcionalidad, para lo que insistimos en la necesidad de análisis de las condiciones de formación del depósito.

\section{TIPOS DE YACIMIENTOS SUPERFICIALES}

No todos los yacimientos de superficie responden a los mismos criterios de formación, y en consecuencia, no todos han de analizarse de la misma manera. Como ya indicamos anteriormente, el primer paso para el estudio de los yacimientos superficiales ha de ser el establecer las condiciones que participan en la génesis del depósito que los alberga. En las condiciones del registro influyen procesos de formación y procesos postdepodeposicionales, que quedan englobados en el concepto de tafocenosis.

Los yacimientos del Paleolítico Antiguo de la Meseta se pueden distinguir según su presencia en cueva y aire libre (y dentro de estos, en superficie o en estratigrafía). Sin embargo, los datos de yacimientos en cueva no son muy numerosos, la localización depende de la presencia en la zona de procesos cársticos, no muy abundantes en la Meseta y raros en el área madrileña. Por otro lado, suponemos que muchos de ellos no han llegado hasta nosotros, a causa de las reactivaciones de los procesos cársticos. En cualquier caso, en el centro peninsular hay escasas evidencias de yacimientos en cuevas, (las cuevas de la Ermita y Cueva Millán (en Burgos) (Moure Romanillo y García Soto, 1993), Atapuerca (Bermúdez de castro, et.al , 1999) o la Cueva de los Casares (Guadalajara) (Barandiaran, 1973) son algunos de los escasos datos con que contamos, especialmente si los comparamos con otras regiones periféricas de Cantabria, Asturias o Andalucía.

De esta manera, la dispersión de los yacimientos de la Meseta se centran en medios fluviales, espacios intensamente prospectados y donde las condiciones de conservación estratigráfica son más favorables (Santonja, 1992).

Los yacimientos de la Meseta central se caracterizan por una ocupación al aire libre, en formaciones cuaternarias y asociados a abanicos aluviales, terrazas, glacis y coluviones, que implican un registro en posición derivada debido a los diferentes procesos postdeposicionales.

La variabilidad de los yacimientos superficiales sin posición estratigráfica es enorme, dependiendo de los tipos de formación del depósito en donde aparecen los yacimientos:

A) Yacimientos en depósitos fluviales (depósitos primarios, más o menos altura o bien redepósitos de mismo origen). 
B) Yacimientos en superficies edáficas

C) Desmantelamiento de parameras por escorrentía (coluviones y depósitos coluvionares).

\section{A) YACIMIENTOS EN DEPóSitos FluViales.}

En la Península aparecen distintas áreas donde se localizan yacimientos en superficie, muchas veces hallazgos aislados, que proceden del desmantelamiento de terrazas, por erosión causada por otros procesos geológicos, pero casi siempre asociados a espacios fluviales.

Los yacimientos ubicados en los desmantelamientos de las terrazas son posteriores a la formación de la misma, distinguiéndose si el depósito se formó en el mismo momento que se depositó la industria lítica, o si los materiales se depositaron una vez desmantelada la terraza. En ambos casos, son necesarios distintos procesos edáficos o erosivos que dejen al descubierto las series arqueológicas.

El yacimiento de Valdegrande (Puebla Yeltes, Salamanca) en la Meseta Norte contiene una industria con apariencia fresca, semi-fresca y alterada/desgastada. Parte de ella está influida por diferentes procesos edáficos, relacionadas con redeposiciones fluviales y afectadas por rodamientos (Santonja, 1986).

Este tipo de yacimiento (desmantelamientos de terrazas, redepósitos) son en ocasiones fácilmente acotables, porque existe una diferenciación geológica que ayuda a delimitar la zona. A pesar de la ausencia de datos estratigráficos, sí es posible una interpretación geológica, que junto con los datos tecnotipológicos, permitan una aproximación cronológica. Existen otros ejemplos de yacimientos superficiales con aprovechamiento de materia prima procedente de rañas y en contextos aluviales, como es el caso del yacimiento Achelense del Rincón (San Muñoz, Salamanca), en la margen izquierda del río Huerbra (Jiménez González et.al., 1987).

En la Meseta sur existen también numerosos yacimientos en superficie relacionados con los medios fluviales, y en especial, en terrazas desmanteladas. El yacimiento de Porzuna, en Ciudad Real localizado junto al río Bullarque (entre los Montes de Toledo y el río Guadiana) se enmarca morfológicamente en una cuenca de depresiones, frecuentemente encharcadas en momentos cuaternarios. La materia prima (cantos rodados de cuarcitas y rocas afines) procede del desmantelamiento de la terraza baja del mismo río, sobre el que se habría desarrollado una intensa actividad de talla.
El material superficial pudo estudiarse gracias a su homogeneidad, e incluso diferenciarse dos conjuntos, uno perteneciente al Achelense Superior y otro al Musteriense de tradición Achelense. En el estudio del material aparecen muchos restos de talla y núcleos levallois, discoides y poliédricos (Vallespí, 1976).

Ciudad Real contiene muchas localizaciones de este tipo de yacimientos superficiales, muchos de estos fueron estudiados por M. Santonja a finales de los 70 y principios de los 80 , que junto con M.A. Querol, recopiló estas estaciones, a veces arduas en su definición. En algunos casos por el bajo número de piezas recogidas, (en ocasiones sin datos estratigráficos) implicando un limitado análisis concluyente. En este sentido, es probable que el resultado no fuese muy informativo tecnológicamente, aunque en cualquier caso, su localización ya implica presencia de grupos humanos en estos ambientes.

Otros estudios sobre series Musterienses han sido realizados en la provincia de Ciudad Real, localizadas en las zonas interiores de las cuencas fluviales y sobre arroyos subsidiarios, en zonas endorreicas o en lagunas cercanas a los afloramientos de materias primas (Ciudad Serrano, 1981-1986). Muchos de los aledaños del río Guadiana, Jabalón o cursos cercanos (Campos de Calatrava) tienen abundante industria paleolítica, generalmente atribuida al Musteriense de Tradición Achelense. Estas estaciones se caracterizan por tener variadas materias primas y localizarse en centros ecológicos bien abastecidos; geológicamente, son productos de desmantelamientos de terrazas (González Ortíz, 1978).

La Casa de la Mina II se localiza en Aragamasilla de Alba, Ciudad Real (Martín Blanco, et al. 1994). En este trabajo se recogió un método de estudio de las series paleolíticas en superficie, analizando al completo las posibilidades de estudio. El yacimiento se ubica sobre un abanico aluvial pleistoceno. Su delimitación es complicada, disminuyendo el tamaño de las piezas y el número de restos líticos aparecidos, en una graduación desde la cabecera hasta el extremo del abanico aluvial. La materia prima tiene su origen en el propio abanico, por lo que destaca su accesibilidad.

Según el estudio de la cadena operativa realizado, este yacimiento podría pertenecer al Paleolítico Medio, aunque los propios autores consideran que en los conjuntos superficiales sin contexto cronológico ni estratigrafía, las atribuciones son arriesgadas (Jiménez Manzanares et.al.; 1995) 
como no podía ser menos. Este tipo de yacimiento, podría considerarse como variante del tipo de desmantelamiento de terrazas. Su génesis va asociada a un alto grado de dispersión en los materiales, que se extienden a lo largo de todo el abanico.

\section{B) Depósitos PRIMARios EN ALtURA (Charcas)}

Uno de los ejemplos más claros es el de los yacimientos superficiales de los paramos del Duero. Se sitúan en dolinas o en cauces de los antiguos valles, hoy en día desaparecidos, que se corresponderían con la antigua red de drenaje del Duero, a comienzos del Pleistoceno. Estas zonas de drenaje acumularían aguas durante los periodos con alta pluviosidad, formando charcas y lagunas en las zonas donde el nivel freático estaba por encima del actual. Estos espacios contienen abundantes restos líticos, y estarían en asociación con la abundancia de recursos de estos humedales. Una vez desecados, y a causa de los efectos del laboreo agrícola, aparecen actualmente en superficie (Díez Martín, 2000).

La interpretación de estas antiguas charcas asume su función como centros referenciales, que contienen restos líticos asociados a los recursos ecológicos. Son áreas de captación de superficies cársticas, de funcionalidad similar a Camino de Salmedina, pero con distinta composición en sus categorías líticas: la materia prima no aflora de forma natural en estas parameras, sino que ha sido transportada desde lugares cercanos.

$\mathrm{El}$ autor realiza un estudio comparativo muy interesante para la interpretación de los materiales en superficie. ¿Asistimos a una interpretación de los mismos como sitios de ocupación o campamentos, o por el contrario se trata de simples áreas de aprovechamiento de recursos? (Díez Martín, 2000). En todo caso, estas áreas (charcas interiores), a pesar de las limitaciones interpretativas, presentan un papel funcional claramente diferente de aquéllos yacimientos relacionados con procesos de desmantelamiento de terrazas. Contamos igualmente con ejemplos parecidos en la zona de el Royo dentro de la provincia de Soria (com. Personal Sergio Bárez).

\section{C) Desmantelamiento de PARAMERAS POR CAUSAS DE COLUVIONES Y ESCORRENTÍA.}

El cerro del Molino de San Cristóbal (Camuñas, Toledo) también se constata como un centro de captación y talla del Paleolítico Medio. En este caso, los materiales se asocian a un depósi- to de ladera o coluvión cuaternario; el afloramiento del material cuarcítico aparece en el propio yacimiento. De nuevo, un yacimiento en superficie aparece asociado, como viene siendo frecuente, a las propias fuentes de materia prima (López Recio, 2000).

En el yacimiento de La Coca (Aspe, Alicante) se localizan conglomerados con nódulos de sílex, en depósitos de ladera asociados a glacis. La industria se encuadra dentro del Paleolítico Medio, presentando piezas con huellas férricas de arado, que producen melladuras mecánicas. La funcionalidad de este espacio se asimila a un lugar de aprovisionamiento de materias primas y talla (Fernández Peris, 1998).

El último tipo de yacimiento en superficie es el más difícil de reconocer si los procesos de escorrentía son poco visibles actualmente, tal como sucede en Camino de Salmedina. Estos procesos son únicamente reconocibles por las alteraciones en la industria lítica, donde se manifiestan dobles pátinas y rodamientos. Sin embargo, y gracias al modelo hidrológico aplicado a la zona, con ayuda de los SIG, podemos llegar a reconocer este tipo de procesos, con intervención de arroyada y escorrentía.

Es interesante insistir en la principal dualidad ofrecida por el Paleolítico Medio peninsular, que es la existente entre series al aire libre superficiales y las procedentes de las cuevas. De este modo, las industrias musterienses de las zonas fluviales se relacionan en su mayoría con áreas de aprovisionamiento de materias primas. En sus categorías líticas, aparecen escasos útiles configurados, estando la mayoría en proceso de elaboración. Ofrecen así un aire más arcaico.

Estas diferencias entre el Musteriense del centro peninsular al aire libre y los conjuntos en cuevas, puede explicarse por una continuidad en el patrón de las ocupaciones, que desde el Paleolítico Inferior presenta localizaciones centradas en ambientes y recursos fluviales, que son continuadas en un "Musteriense de Graveras", el paso de uno a otro horizonte no habría sido tan drástico como en las series de las cuevas, donde los niveles de Paleolítico Inferior se distinguen claramente de los horizontes posteriores (Vallespí, 1989).

\section{YACIMIENTOS EN SUPERFICIE LOCALIZADOS EN EL ÁREA DE MADRID.}

En la cuenca baja del río Manzanares junto con el área de confluencia del río Jarama, aparecen un gran número de yacimientos superficiales, 
de difícil limitación, situados sobre el páramo terciario (margen izquierda del río Mazanares, a la altura de Vallecas villa), donde se puede observar los cerros testigos de época miocénica con afloramiento de sílex, (Almódovar, Los Ángeles, Telégrafo, etc.) que a su vez contienen yacimientos superficiales (Cobo, et al. 1979, Gamazo 1982).

Muchos de estos cerros testigos que componen el paisaje de la zona sur de Madrid, fueron destruidos y demolidos por las urbanizaciones y la creación de nuevas industrias en las afueras de la ciudad, lo que provocó la destrucción de más yacimientos de este tipo ${ }^{1}$. El caso de los yacimientos de la margen izquierda del Manzanares parece distinto. Su formación se origina por otras causas, y en ningún momento se observan retazos de terraza en esta margen meridional del río, o a los bordes de los cerros testigos, donde se ubican estos yacimientos. Esto no quiere decir que no tengan que ver con causas fluviales o de escorrentía, ya que uno de los atributos característicos en este tipo de material son los distintos grados de rodamientos, al igual que las incrustaciones de carbonatos que indican contacto con agua. Sin embargo, todavía no ha sido explicada en profundidad la génesis de dichos yacimientos.

Se posee gran cantidad de documentación antigua sobre la presencia de tales yacimientos desde principios de siglo. En muchas de las publicaciones sobre las recogidas se documentan, además de restos líticos trabajados, grandes bloques de sílex sin tallar (Pérez de Barradas, 1921a, 1921b). Hacemos referencia a este aspecto porque es un rasgo que viene repitiéndose en casi todos los yacimientos superficiales, en relación con la existencia de áreas de aprovisionamiento y talla en los alrededores de los cauces fluviales más importantes de la región.

La mayoría de estos conjuntos superficiales, fueron descubiertos en las excursiones de J. Pérez de Barradas en compañía de $\mathrm{P}$. Wernet y $\mathrm{H}$. Obermaier, entre otros. En estas publicaciones se documentan la recogida de materiales superficiales en distintas áreas, casi todas comprendidas en los términos de Vallecas, Mejorada, Rivas y Santa Eugenia, aunque también recorrieron otras zonas, como la Casa de Campo. Del cerro Almodóvar encontramos esta cita de Pérez de Barradas: "...Cerros testigos terciarios continua-

1. En la actualidad la zona estudiada esta sufriendo los mismos efectos destructivos que los yacimientos descubiertos a principios de siglo. El Ensanche de Vallecas, futura ciudad, con todas las infraestructuras necesarias de las ción de este van paralelos a la carretera de Andalucía; pero sus lados y cimas son cuaternarios en este terreno hemos encontrado sílex tallado de aspecto Musteriense" (Pérez de Barradas 1929:221)

El Primer trabajo donde aparecen estos yacimientos es "Nuevos yacimientos paleolíticos de la superficie de la región de Madrid" (Pérez de Barradas, 1919), que documenta sílex tallado situado sobre niveles del Mioceno, al pie de los cerros testigos. Según el autor, todos estos materiales de los alrededores de Madrid (hoy ya ubicados dentro de la capital) se disponen al descubierto por la acción erosiva de las aguas, por el arado o por otras acciones humanas. La riqueza arqueológica de la zona queda reflejada en las palabras de Pérez de Barradas: "Varias veces he tenido ocasión de insistir sobre el hecho que toda la porción inferior del Valle del Manzanares es un inmenso yacimiento paleolítico, bien "in situ", esto es, entre las capas del terreno, o bien en superficie del mismo" (Pérez de Barradas 1924: 28).

\section{Procesos postdeposicionales en los YACIMIENTOS SUPERFICIALES.}

En todos los yacimientos en superficie los procesos postdeposicionales son los causantes de las alteraciones en el registro arqueológico. Entender el funcionamiento de los mismos, permite establecer categorías dentro de la industria en busca de la homogeneidad.

La actividad agrícola es una de las más características causas de alteración de los depósitos. La zona de estudio se encuentra en una superficie de campos de labor. Por ello, a los procesos sedimentológicos y geomorfológicos se le une el laboreo desarrollado sobre estos espacios. Los yacimientos arqueológicos en zonas cultivadas presentan una mayor visibilidad del terreno por la ausencia de capa vegetal, en momentos de la siembra o barbecho. Los estudios de yacimientos arqueológicos situados en campos de labor, han sido escasos en nuestra Península y únicamente las investigaciones anglosajonas han dado alguna pauta para abordar las localizaciones y descubrimientos en estos medios (Baker, 1978).

A pesar de las limitaciones que el uso agríco-

grandes urbes modernas, carreteras, metro, pisos y grandes superficies comerciales, está siendo construída y su paisaje drásticamente modificado. 
la impone en el estudio de yacimientos de superficie, parece demostrado que el laboreo no imprime en los materiales desplazamientos geográficos acusados. La actividad agrícola produce desplazamiento horizontal y vertical de los materiales, que por cada operación no debería superar los $15 \mathrm{~cm}$., y aunque en un principio, se produjese una selección por el tamaño de las piezas (percolando las piezas de menor tamaño y elevando las de mayor tamaño), después de un largo proceso de actividad agrícola estas diferenciaciones acabarían por ser inapreciable. Por otro lado la mecánica de desplazamiento es constate en los yacimientos que sufren estos procesos; el recorrido horizontal es siempre limitado (Diéz Martín, 2000).

La actividad agrícola actuará de manera homogénea en cualquiera de las variantes de yacimientos anteriormente expuestas. En el caso de las parameras del Duero, afectadas igualmente por actividades agrícolas, la intervención del arado sobre las piezas líticas podría ser la misma a yacimientos como Camino de Salmedina, a pesar de una génesis diferente para los depósitos. Las actividades de laboreo generan acumulaciones de materiales que nada tienen que ver con los patrones de dispersión originales, determinados por los gradientes topográficos. El laboreo permite acceder a una muestra de población real, aunque posea un sesgo importante. El laboreo puede enmascarar y uniformar los datos, pero no altera el orden de las diferentes partes que componen el puzzle del yacimiento original (Diéz Martín, 2000).

\section{EL YACIMIENTO Y SU CONTEXTO GEOLÓGICO}

El yacimiento en superficie del Camino de Salmedina $^{2}$ se encontraba ubicado al sur de Vallecas Villa, (Madrid), dentro de un paraje conocido como Zapata, próximo al propio Camino de Salmedina. Dado el estado actual del yacimiento y de los terrenos en que se ubicaba no resulta en la actualidad posible el reconocimiento de su posición original. Se encuentra en la zona meridional de la margen Izquierda del río Manzanares, en concreto sobre la llanura de Vallecas.

Dicho lugar está compuesto básicamente por

2 El yacimiento en superficie del Camino de Salmedina, se encuentra hoy en día arrasado y destruido por las obras del ensanche de Vallecas, lamentamos profundamente la destrucción de esta zona tan rica y conocida margas sarmatienses, en su mayoría yesíferas dando al paisaje un aspecto árido de estepa salina. La zona sur de Vallecas contiene litofacies de yesos y arcillas correspondiendo a un lago salino de época miocénica. Estas litofacies contienen una densidad muy amplia la cual ha sido atravesada más de $100 \mathrm{~m}$, sin llegar a la base de está unidad (Pérez González y Calvo, 1989). Esta formación miocena, esta formada por distintas unidades: una inferior compuesta por arcillas yesíferas, y una superior denominada en antiguo como "peñuela" donde predomina la sepiolíta y el sílex (Royo Gómez, 1929).

El cuaternario de la zona se compone de arenas más o menos arcillosas (amarillo-rojizas) y arenas cargadas de caliza, formando margas silíceas en lentejones o capas más o menos extensas. Sobre los niveles del mioceno, las arcillas parduscas o rojizas están divididas por la sequedad (con aspecto de prismas vegetales, tradicionalmente denominados "canutillo").

El proceso de relleno de la zona comienza en momentos cuaternarios, observables en los cortes de las trincheras de Vallecas, donde los yesos miocenos a causa de la disolución cárstica, provocan cavidades que posteriormente han sido rellenadas (Obermaier et.al., 1921). La zona esta plegada según J. Royo Gómez durante el terciario, produciéndose estos rellenos en momentos cuaternarios (Royo Gómez, 1923). En realidad muchos de los contenidos de estos rellenos de la cavidades yesiferas, también incluyen restos industria lítica, con las mismas características que las encontradas en la superficie (Obermaier et.al., 1921).

El lugar donde se ubica el yacimiento se enmarca en una zona de dolinas, formadas a causa de procesos de disolución cárstica, produciendo cavidades (de contorno ovoide y en ocasiones de dimensiones bastante amplias) y conductos internos difíciles de precisar. A medida que se superan las resistencias por tensiones y esfuerzos se produce el desplome y caída del techo, como sucede en el caso de cumbres de Vallecas. Las dolinas se instalan sobre los yesos miocenos y a veces afectan a materiales carbonatados superiores, los rellenos, de las depresiones que forman su paisaje, son arcillo-limosos con algo de arenas, y como ya dijimos, de restos de

desde principios de siglo (Obermaier et.al., 1921, Obermaier, 1925) (Pérez de Barradas, 1926 y 1929) en yacimientos de superficie del Paleolítico y quizás del Postpaleolítico. 
pedernales (sílex). Es precisamente esta circunstancia, en relación con su proximidad a los cerros testigos, la que ha influido en gran medida en la formación posibles palimpsestos cuaternarios, sobre los que la actividad humana ha tenido lugar ( Conde et al., 2002, López Recio, et al. 2005) esencial para reconstruir la dinámica de captación de materiales líticos en esta zona del Río Manzanares durante el Paleolítico antiguo. No obstante la dinámica descrita ha enmascarado en gran medida, los rasgos que permiten en la actualidad establecer que factores han intervenido a lo largo del tiempo en la génesis del depósito del Camino de Salmedina.

\section{MODELO APLICADO}

Con el fin de establecer o al menos discriminar, las causas que han determinado la acumulación actualmente existente en el Camino de Salmedina, y a falta de un sondeo que permitiera afinar más aún las condiciones sedimentarias en que se enmarca el conjunto, optamos por aproximarnos al problema mediante la utilización de herramientas SIG, y más concretamente, mediante la reconstrucción del modelo hidrológico existente en la zona.

Los Sistemas de Información Geográficas se definen como herramientas informáticas que permiten la organización, manipulación, análisis y recuperación de la información geográfica. Basándose en elementos cartográficos junto con elementos alfanuméricos (bases de datos). En un proceso llevado a cabo por un sistema que establece una nueva información geográfica diferente de la de partida. Para ello los elementos claves de partida son los datos (Baena, et.al. 1999).

En el modelo que presentamos se ha empleado, en concreto, una aplicación del programa ArcView (módulo Spatial Analyst). Este programa es uno de los más desarrollados y más utilizado en aplicaciones de SIG en arqueología. los objetivos básicos que pretendemos obtener son los siguientes:

a) Registro de los datos de campo

b) Análisis de la distribución de los registros

c) Correlación la misma con otros factores mediante la creación de modelos aplicables en la zona de estudio.

3 Agradecemos enormemente la amabilidad del Servicio Cartográfico Regional de la CAM en la persona de

\section{Proceso de trabajo}

Como punto inicial conviene precisar que el modelo que planteamos parte de una base cartográfica altimétrica actual y por lo tanto se trata de una mera aproximación a las causas que pudieron intervenir en la distribución de los registros actualmente localizados. De hecho, el ensayo plantea para la zona de estudio (tramo final de la margen izquierda del río Manzanares), la hipótesis de que el modelo altimétrico para el Pleistoceno no ha sufrido cambios sustanciales en sus puntos (Silva, 2003). Suponemos por tanto que los datos de elevación, en líneas generales, no han cambiado sustancialmente la relación topográfica del área desde fases del Pleistoceno Superior. Por otra parte el área de estudio ha sido hasta la actualidad una zona escasamente urbanizada, lo que motiva que no se hayan detectado cambios destacados en la topografía como resultado de la actividad humana.

Así, la altimetría pertenece a la cartografía escala 1:5000 de las hojas 559, 582 de la Comunidad de Madrid, estas hojas fueron obtenidas en formato digital del Centro Cartográfico Regional de la Comunidad de Madrid ${ }^{3}$.

El registro de los testimonios arqueológicos fue realizado mediante una prospección intensiva de campo. Dicha prospección se dividió en un total de 11 zonas arqueológicos, subdivididas a su vez en 72 cuadriculas de $250 \mathrm{~m}$ x $250 \mathrm{~m}$. (divididas en 8 columnas y 9 filas). Los datos obtenidos se consiguieron analizando las densidades de material arqueológico de cada zona. Estas densidades se establecieron en función de cuatro valores, según el grado de menor a mayor intensidad: 0 la intensidad nula, 1 intensidad baja, 2 intensidad alta, 3 intensidad muy alta y 4 intensidad extrema. Aunque la metodología de prospección fue uniforme, muchas de las zonas prospectadas fueron difíciles de evaluar por las condiciones del terreno (García Sanjuán, 2005), pero con ayuda de la carta arqueológica pudimos representar las densidades en una malla como observamos en la figura 1.

Una vez registrada la distribución de densidades de artefactos sobre la planimetría, propusimos como hipótesis de trabajo, que dicha acumulación pudiera responder a la existencia de cauces relictos en la zona. Para ello, dentro del módulo Spatial Analyst empleamos un modelo

Rafael Herrero, que nos suministró toda la documentación cartográfica necesaria para el trabajo. 
concreto de análisis de superficies de fricción. Estos modelos de reconstrucción hidrológica, analizan el resultado de la dirección de descenso del agua, determinada por la morfología de la superficie. Está función parte de una grid o malla de puntos con las distintas elevaciones obtenidas a partir de las curvas de altimetría. A partir de estos datos, el programa analiza y reconstruye las diferentes líneas de escape del agua desde el modelo generado.

Los pasos a seguir para calcular las acumulaciones de agua en celdas, y posteriormente las redes hidrológicas para su comparación, son los siguientes:

Integración de bases cartográficas de la zona, para a continuación, con ayuda de los datos altimétricos, generar MDT (modelo digital del terreno) que da paso a una grid o malla de puntos altimétricos (Fig.2), esta será la base cartográfica donde se calculará el modelo hidrológico.

- El segundo paso es generar (formato grid), una base con las direcciones de corriente para cada píxel ( o Flowdirection). Esta computa en distintas celdas las direcciones de fluido a lo largo de toda la topografía del terreno seleccionada (Fig.3).

- El tercer paso de la aplicación será el relleno de zonas deprimidas (todas las áreas de drenaje interno), con el fin de dotar de continuidad el modelo de escape de agua y con ello obtener una red continua de drenaje. Esta opción resulta igualmente interesante de cara a detectar igualmente zonas endorreicas si bien en nuestro caso optamos por el relleno dado que los materiales prospectados presentaban claras muestras de haber sido transportados.

- El cuarto paso consiste en generar las teselas hidrográficas (watershed) a partir del drenaje creado (Fig.4 y 5). Este paso sería innecesario si lo que se pretendiese es el localizar un único arroyo en la zona, pero necesario para una red más amplia.

- La red de drenaje se crea a partir de un modelo de acumulación hidrológica o flowacumulation (Fig.6 y 7), que calcula el trazado

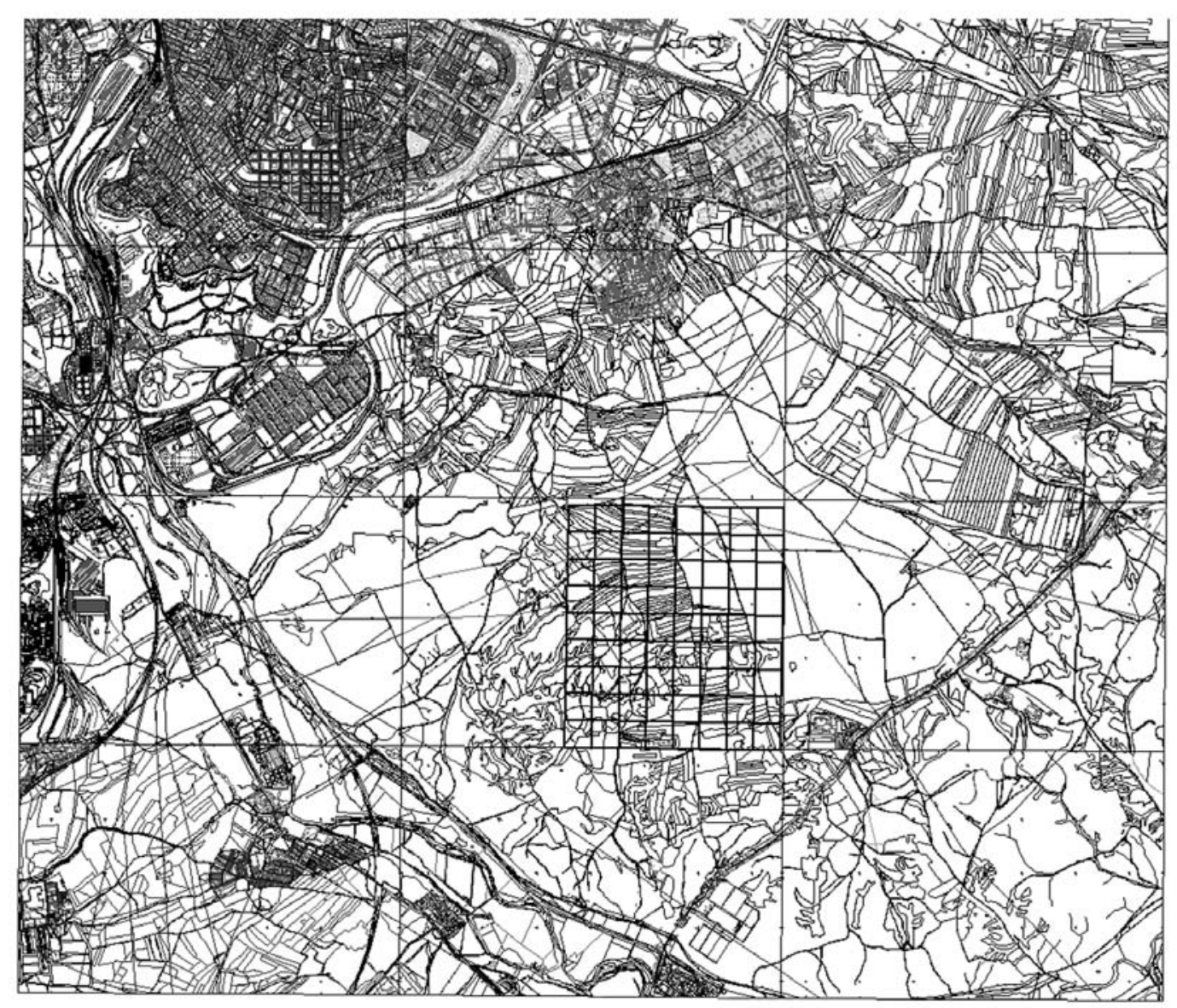

Fig. 1 - Planimetría de la zona y área prospectada 
general del drenaje para la zona a partir de la Flowdireccion de la topografía del terreno.

- El último paso consiste en generar límite de los distintos arroyos. El programa produce diferentes segmentos que unidos, gracias al relleno de las zonas endorreicas, acabarán por formar la red lineal de drenaje. Esta supuesta red lineal se debió aproximar bastante al último modelo fluvial existente en la zona (Fig 8).

Una vez obtenido el modelo hidrológico es posible superponer al mismo los resultados de la malla de las cuadriculas prospectadas, así como los datos cuantitativos y cualitati-

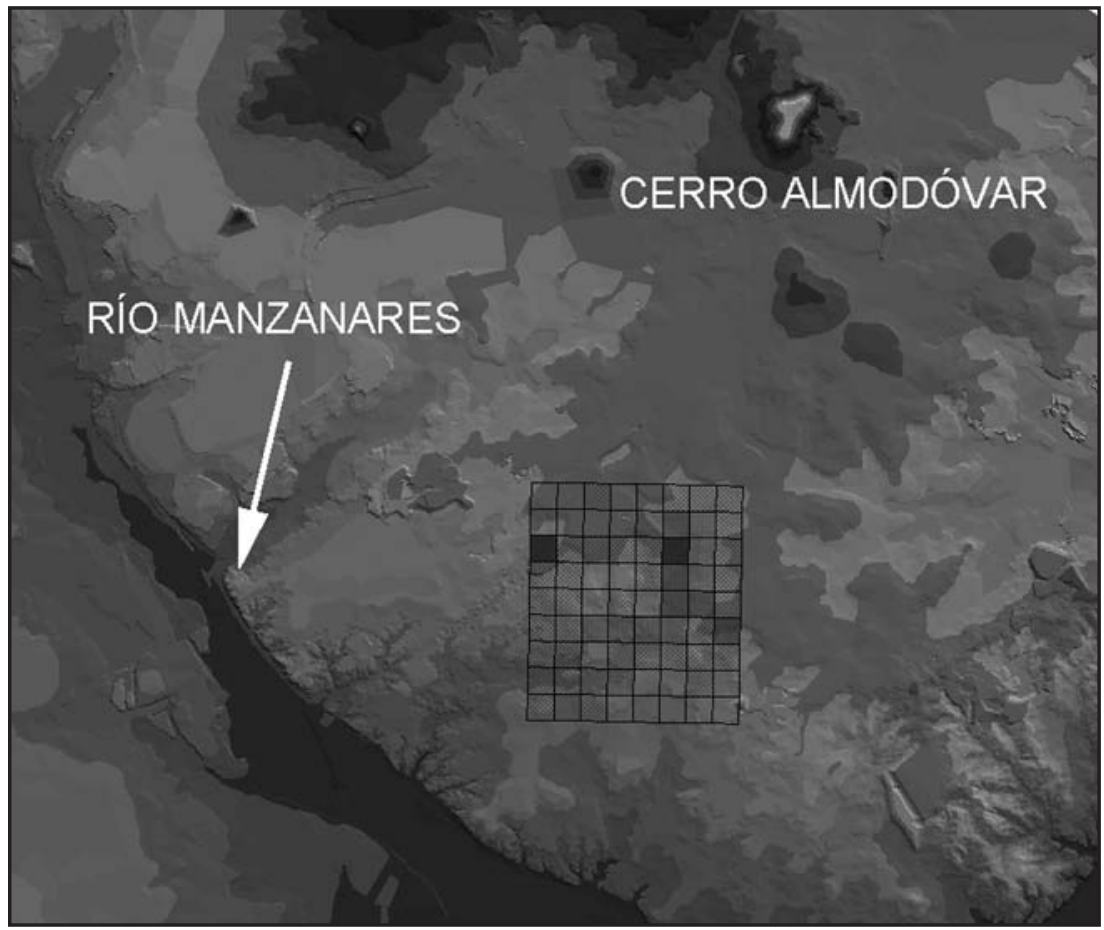

Fig. 2 - Zona de prospección sobre el MDT (Tin) vos de los materiales recuperados con el fin de realizar un análisis comparativo del solapamiento de ambas capas tal y como mostramos en la figura 9 en la que se representan sobre el modelo las densidades de material recuperadas en superficie.

\section{RESUltados DEL MOdelo HidROLÓGICO EN EL ÁREA DE ESTUDIO.}

El objetivo de este SIG ha sido constatar el posible comportamiento del agua en forma tanto de arroyada, como de escorrentía, dentro de la zona de estudio, con el fin de correlacionar dicho modelo con el registro de densidades de artefactos. Como explicamos anteriormente todos los datos del terreno son actuales. Sin embargo, parece que la variación del terreno debida tanto a agentes erosivos, como a la actividad antrópica no ha enmascarado los principales signos de identidad del paisaje durante el Pleistoceno superior.

Las formaciones de glacis y de terrazas establecidas en la cuenca del río Manzanares se desarrollaron durante el
Pleistoceno, pero en la margen izquierda, (donde estas formaciones no se documentan claramente) los procesos tectónicos han ido destruyéndolas quedando únicamente una superficie endorreica de época cuaternaria. El clima, aunque muy parecido al actual, poseía un grado de humedad mayor (PÉREZ GONZÁLEZ y CALVO, 1989), provocando arrastres de agua bastante fuertes, que como resultado formarían

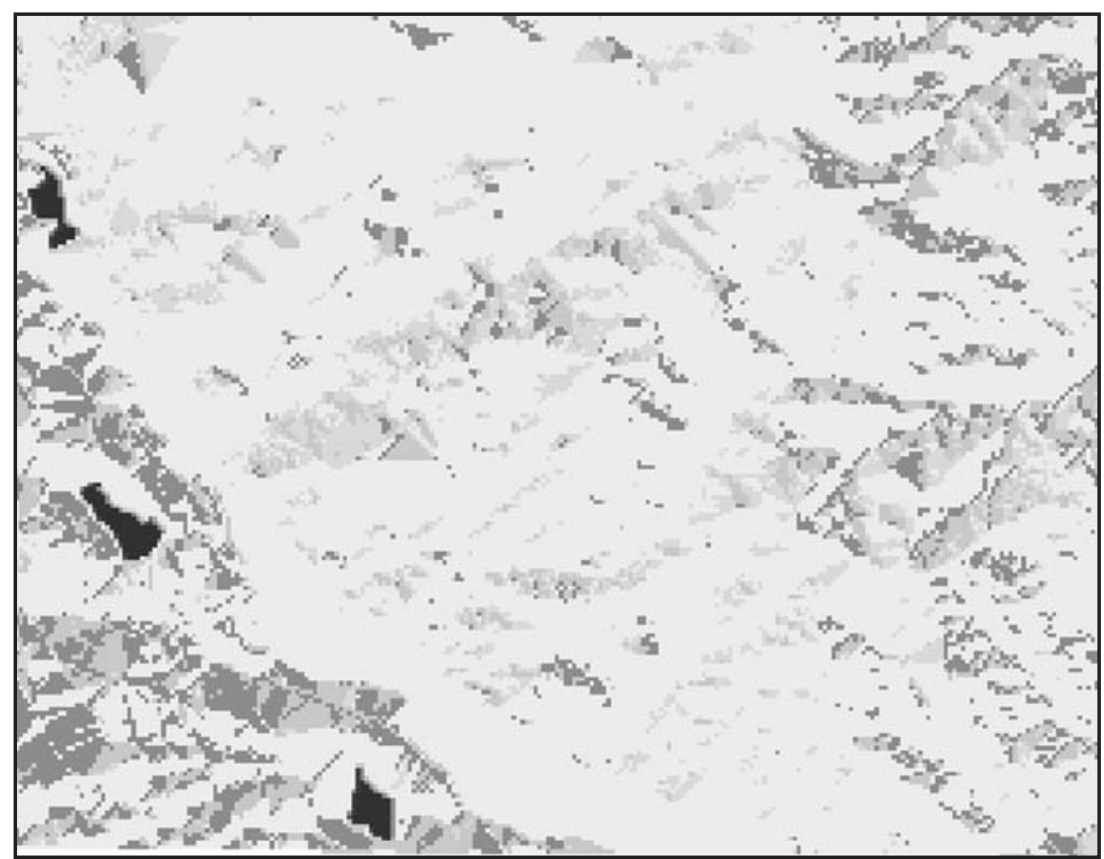

Fig. 3 - Flowdirecction 40, proceso para determinar la dirección de los cursos de agua sobre la grid. 


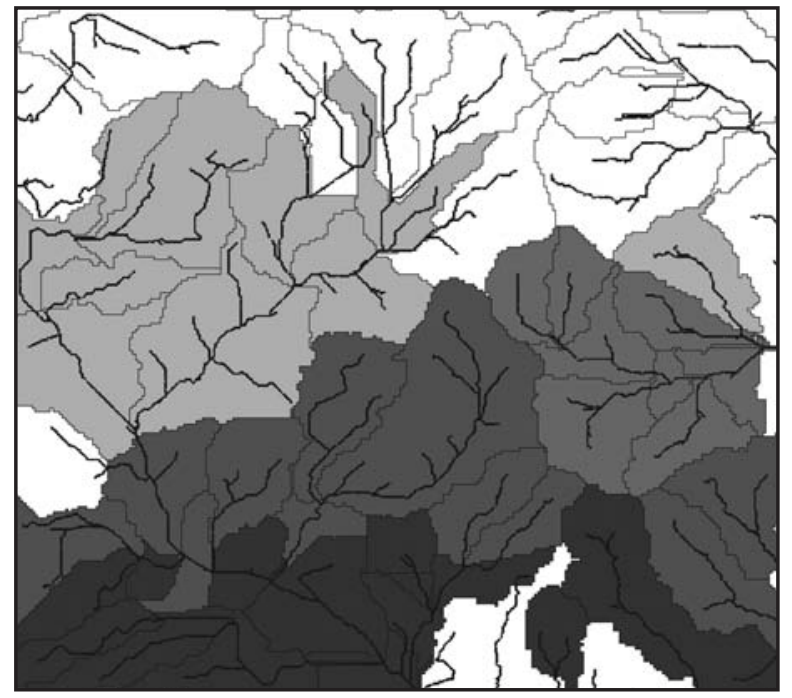

Fig. 4 - Watershed, reconstrucción como áreas de acumulación indicando una resolución de 40.

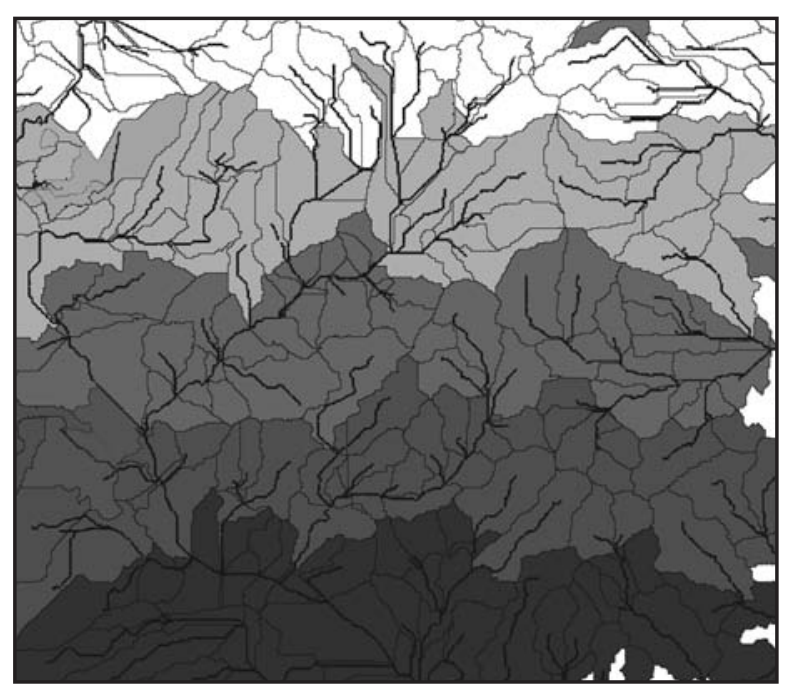

Fig. 5 - Watershed, reconstrucción como áreas de acumulación indicando una resolución de 20.

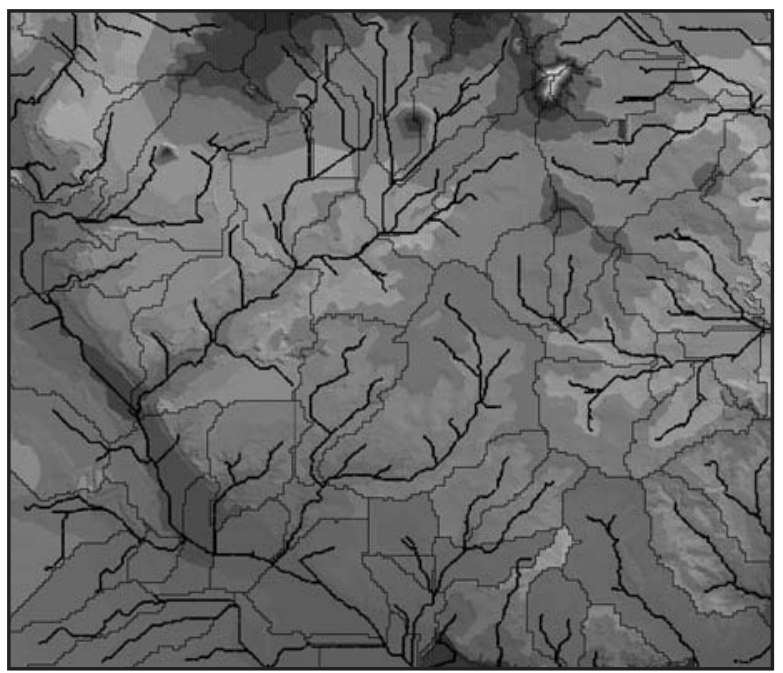

Fig. 6 - Reconstrucción del modelo hidrológico a resolución 40

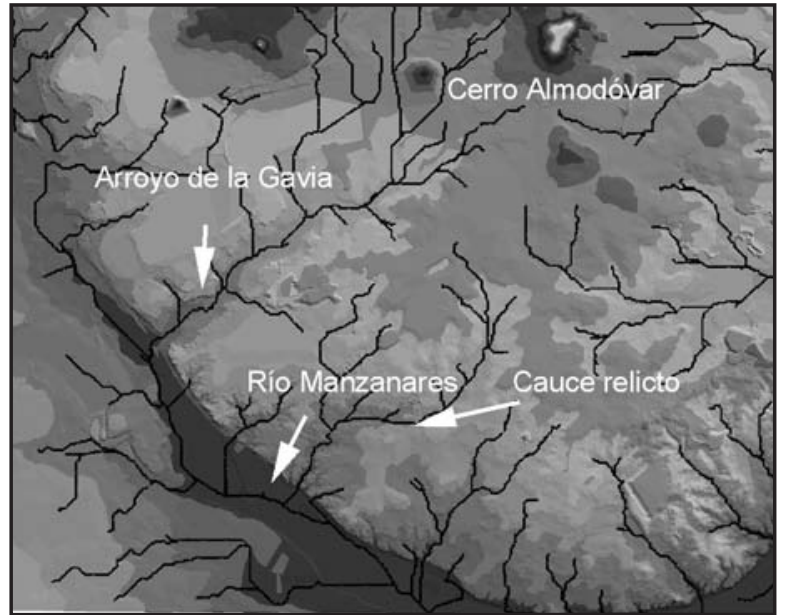

Fig. 7 - Reconstrucción del modelo hidrológico a resolución 20

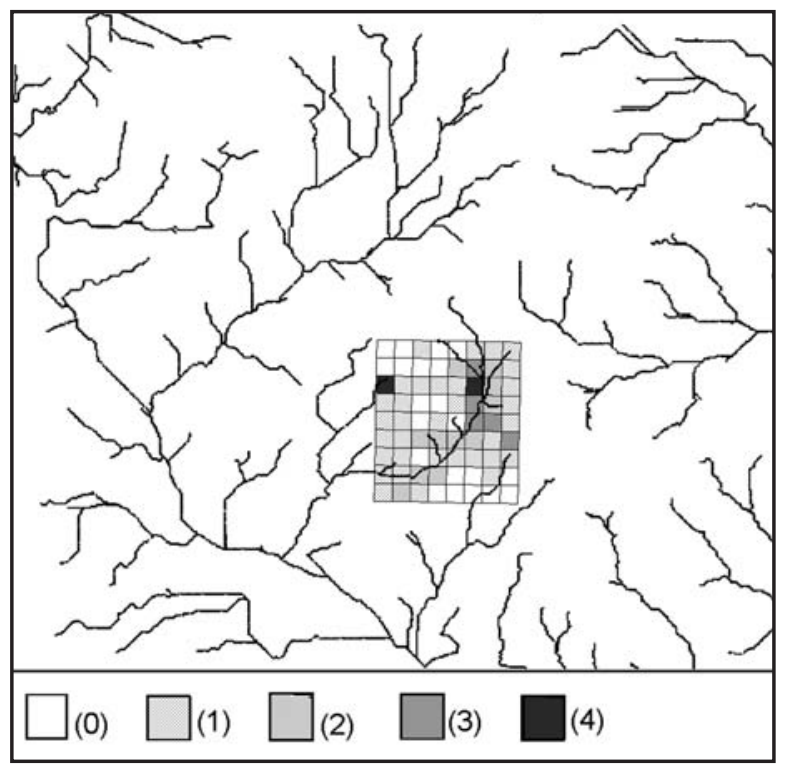

Fig. 8 - Modelo hidrológico sobre datos de densidad de la industria recogida en la prospección.

arroyos que desembocarían en el cauce principal (Fig 2). Este tipo de arroyos no han dejado vestigio alguno en la zona, pero las huellas que aparecen en la industria de superficie testimonian la presencia de cursos y de arrastre (pátinas de rodamiento, carbonataciones). Por esta razón pensamos que el modelo presentado se ajusta razonablemente al modelo geomorfológico existente para la zona.

Por otro lado, los modelos de captación de recursos líticos propuestos para la región (Baena et.al., 1997), también cuadran con el modelo de reconstrucción presentado, dada la relación existente entre los agregados registrados en la prospección, el cauce reconstruido, y el afloramiento del Cerro de Almodóvar. Partiendo de este punto, donde aparecen los 


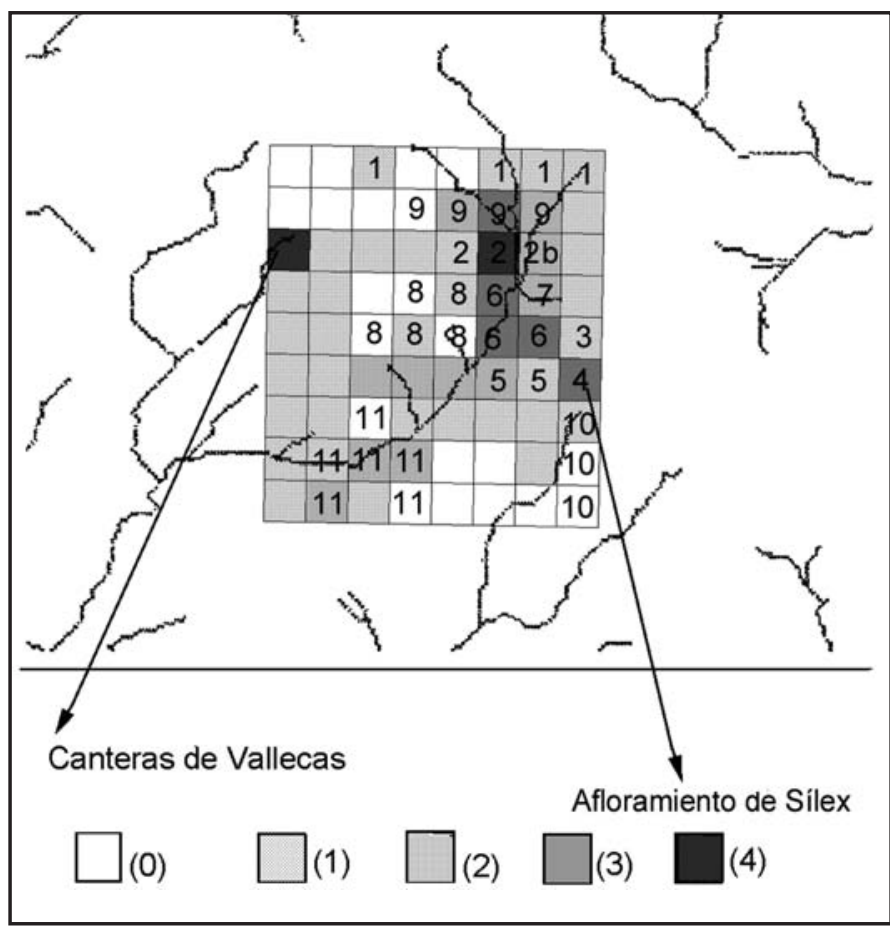

Fig. 9 - Detalle de la figura 10 con los datos de densidades de material y las distintas zonas prospectadas.

nódulos de sílex (el cerro Almodóvar), se producen unos procesos erosivos y de arrastre fuerte que disgregarían la materia prima esparciéndola por toda la superficie. Sabemos, que casi toda la zona de los alrededores del cerro tiene industria lítica en superficie junto con nódulos de sílex sin tallar. Por esta razón nos inclinamos a pensar que el lugar pudiese actuar como un reclamo muy atractivo para la captación de estos grupos primitivos. Existiendo así dos tipos de modelos posibles:

1) Los grupos humanos se acercan a los alrededores del cerro y luego por causas erosivas y de arroyada se disgregan los restos líticos dispersándose por toda la zona.

2) Los grupos humanos se acercan a los alrededores del cerro y también a las áreas dispersas.

Parece, por los datos de alteración obtenidos en la industria donde existen diferentes rodamientos, roturas de pátina, melladuras y pseudorretoques, que nos encontramos frente al segundo modelo, si bien la diacronía de estos conjuntos habilita ambas opciones.

La figura 10 viene a resumir los datos con que contamos. Por un lado el cauce principal o río Manzanares, por otro el arroyo de la Gavia, y junto a ellos, el modelo hidrológico con los cauces relictos. La correlación existente (igualmente alta para el caso de Canteras de Vallecas) apunta en el sentido de entender como éstos, son los causantes de la dispersión de los restos en superficie. Por otra parte, observamos como los cauces relictos parten, en su mayoría, de los alrededores de cerro Almodovar (Fig.6). Teniendo en cuenta que el cerro es la cota más alta de la zona, todo hace pensar que la cabecera de estos arroyos se iniciase allí mismo, con las consecuencias, en cuanto a transporte de litologías, que ello conlleva.

Las intensas alteraciones nos sugieren como la existencia de cauces partiendo del cerro, además del desplazamiento de los bloques del sílex, alterarían los posibles yacimientos que allí se generasen. La existencia, como hemos comentado, de innumerables testimonios en la zona acreditados por los datos de la Carta Arqueológica de la Comunidad de Madrid, los presentados por Pérez de Barradas, los resultados de la reciente excavación M-45 o los yacimientos de la carretera de Valencia (Marquéz Triguero, 1965), confirman el carácter del cerro como área central de actividad de talla en la zona.

Dado que todo el proceso de prospección en el Camino de Salmedina se realizó con anterioridad al modelo hidrológico, resulta sorprendente el resultado de la aplicación. La figura 9 muestra en un detalle de la reconstrucción del cauce relicto, como éste pasaría justamente por las zonas del yacimiento de Camino de Salmedina. De hecho la mayor concentración de material dentro del yacimiento se produce en la propia delineación del curso reconstruido. Los datos del yacimiento nos indican que se produjo una mezcla importante de materiales, procedentes de distintas aportaciones a lo largo del tiempo (a veces incluso en momentos coetáneos). No obstante la concentración de los testimonios confirman que el modelo de arroyada difusa no parece no ser el principal agente causante del depósito, ya que en ese caso la dispersión de los materiales hubiera sido mucho mayor.

Sólo si la zona tuvo una relativa actividad fluvial con posibles fases de intenso drenaje, podemos entender la dispersión de industria lítica tallada y sin tallar en el Camino de Salmedina. Los distintos yacimientos en superficie (figura 11 a), la gran intensidad de materia prima disgregada en la zona, y la distribución de tipos y alteraciones en los mismos dentro del yacimiento 


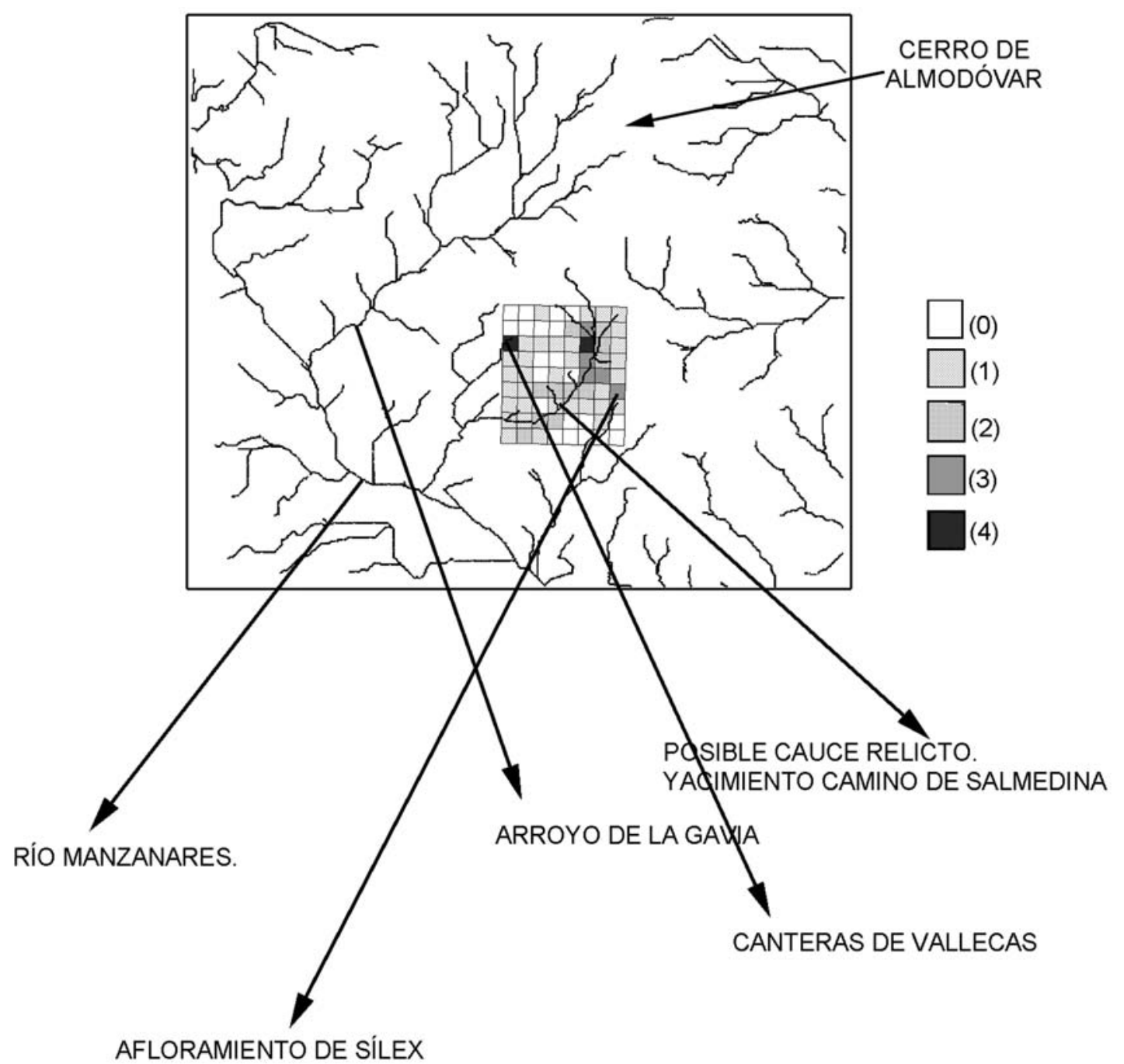

Fig. 10 - Localización de los distintos cauces en el modelo hidrológico junto a los datos de densidad de la zona prospectada.

(figura 11 b) lo constatan. El modelo hidrológico sugiere que los procesos de disgregamiento de las materias primas (en este caso el sílex) han sido causados por arrastre a partir de puntos de extrema agregación (Cobo y Gamanzo, 1983).

Parece evidente que el carácter de este tipo de yacimientos en superficie encuadrados en el paleolítico antiguo son en general de áreas de captación. Como se viene observado en la bibliografía, dicha captación se perfila como un fenómeno local, inmediato, tanto en ambientes fluviales al aire libre, como en yacimientos en cueva. Se observa una continuidad en las estrategias durante el Paleolítico Inferior y Medio, más acusada en los yacimientos al aire libre que en los yacimientos en cueva. En éstos se pude observar un modelo de aprovechamiento más específico en la elección de materias primas, que se ajustan con más precisión al objetivo deseado
(Vallespí, 1989), mientras que en los yacimientos al aire libre la materia prima decrece en exigencia, aprovechándose un alto rango de calidades de carácter local.

En los modelos de captación presentes en la cuenca baja del Manzanares podemos observar una diferencia clara entre dos ámbitos diferenciados en cuanto a sus litologías y morfologías básicas. En el primero de los casos en la margen derecha, la mayoría de las localizaciones (Arriaga, Orcasitas, Transfesa) responden a un aprovechamiento preferente de recursos de tipo animal asociados a captaciones expeditivas sobre depósitos secundarios, en niveles de terraza (entornos fluviales), mientras en el lado izquierdo nos encontramos un aprovechamiento de recursos abitóticos, que, según las categorías de elementos localizados en los yacimientos, responden básicamente a materia prima de sílex, en 
contextos no tan claramente derivados En la mayoría de los casos no se ubican en terrazas, ya que la formación de terrazas en este ámbito es limitada por sus condiciones geomorfológicas.

El carácter de estas localizaciones es claramente el de centros de aprovechamiento y talleres, funcionando como una especie de "supermercados de la piedra" utilizados como centros de visita recurrente durante largos periodos. La

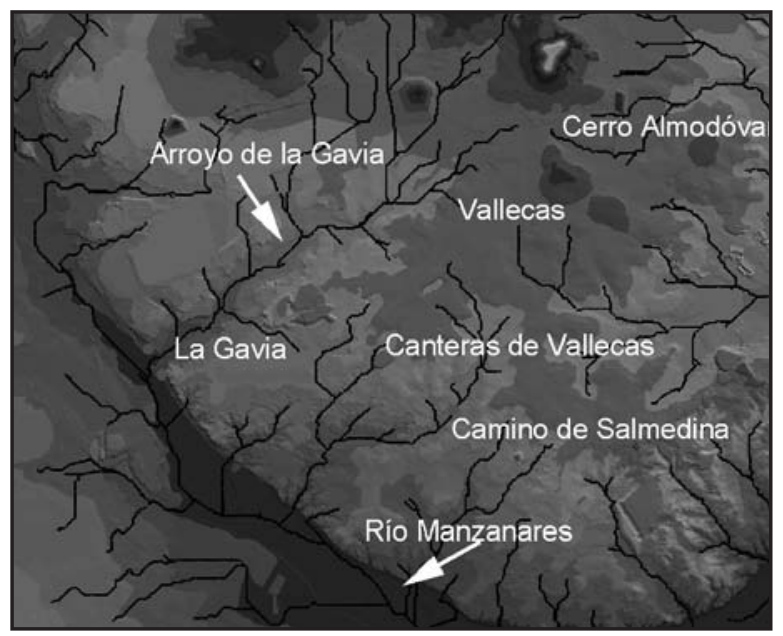

Fig. 11a - Modelo hidrológico sobre el MDT (Tin). en la zona de estudio, con la representación de algunos yacimientos paleolíticos de la zona.

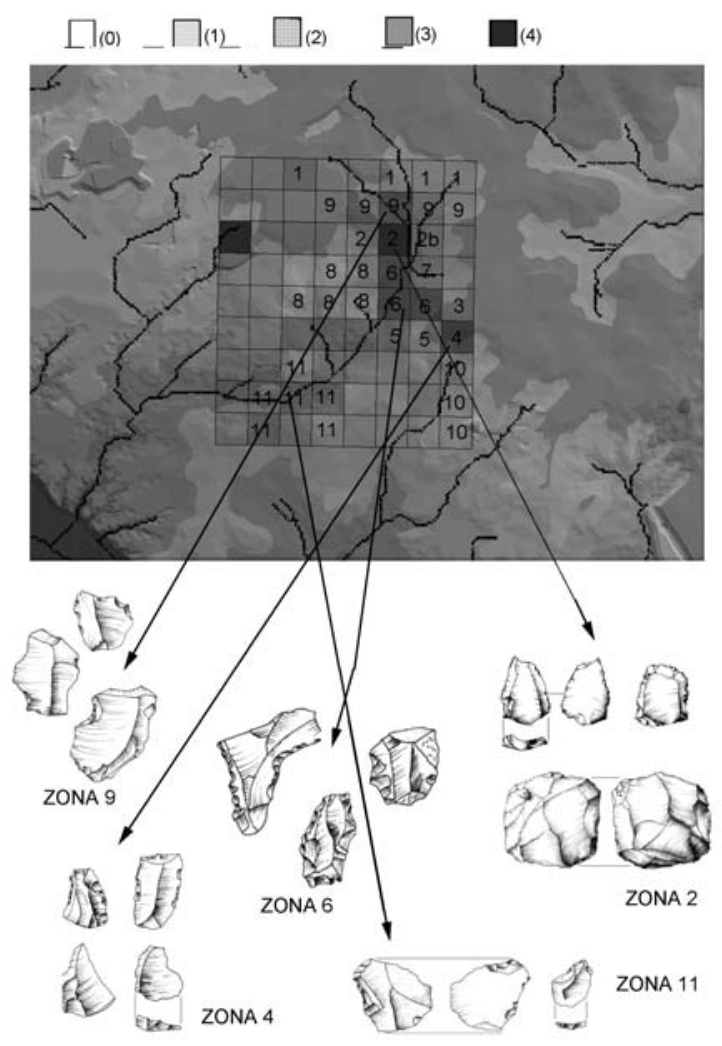

Fig. $11 b$ - Zonas prospectadas y tipos que aparecen en cada zona. yacimientos Camino de Salmedina. dinámica de la zona tuvo un importante papel en este sentido, donde la abundancia de materia prima se vio alterada y extendida, siendo de fácil acceso para los grupos de cazadores recolectores durante el Pleistoceno. En este sentido determinados lugares funcionarían como grandes almacenes, a los que se accedería para una supuesta extracción (aunque sin apenas dificultad) de soportes. Con el tiempo, el aumento de los requerimientos tecnológicos harían necesaria una mayor capacidad de selección de los soportes, solo viable mediante el acceso a grandes concentraciones superficiales, o bien mediante prácticas de minería todavía no acreditadas en la zona durante el Paleolítico Medio y el Paleolítico inferior.

Estos espacios ofrecen categorías de elementos que justifican tal atribución, con un alto porcentaje de núcleos y lascas frente a un bajo porcentaje de útiles. La lógica, así como la asimetría tecnológica de los productos, parecen aludir a la existencia de procesos de aprendizaje (Baena, 1992). Aunque el carácter de estos yacimientos limita las posibilidades de un estudio interno de los mismos, la lógica nos indica que las actividades de aprendizaje debieron realizarse de forma preferente sobre espacios muy ricos en materias primas.

Esta abundancia de materia prima viene definido por distintos tipos de afloramientos que se ofrecen en la zona :

a) Afloramiento natural.

b) Depósitos secundarios intensamente agregados.

c) Depósitos secundarios agregados

d) Depósitos secundarios poco agregados o de baja densidad.

Estas distintas modalidades condicionan el tipo de ocupación, las estrategias, así como las distintas actividades desarrolladas en cada zona.

En los yacimientos en superficie su dificultad de estudio es elevada, porque su coincidencia con zonas de captación implica una acumulación reiterada de restos líticos durante periodos muy prolongados. En este caso, la reconstrucción del modelo hidrológico mediante SIG ayudan a comprender los posibles agentes responsables de la acumulación.

Como hemos podido comprobar en este trabajo, el yacimiento de Salmedina ha sido originado por diferentes arrastres provocados por la acción hídrica y la escorrentía en zonas dotadas 
de una mayor humedad que en la actualidad. El modelo hidrológico ha permitido reconstruir un cauce relicto que coincide con el área de dispersión de materiales tallados, y justifica la presencia de la gran cantidad de materiales en bruto, como resultado de la actividad hídrica general cercana al Cerro de Almodóvar.

El yacimiento que presentamos, cuya génesis puede quedar en gran parte explicada por lo descrito previamente, responde a un modelo muy habitual en la zona madrileña, seguramente explicable en clave de explotación de recursos líticos. Su atribución cultural, definida por el estudio tecnológico ${ }^{5}$ del conjunto, parece adscribirse sin muchas dudas a un Musteriense, a pesar de que hayamos asumido la dificultad de trabajo sobre este tipo de yacimientos por la acumulación de restos líticos durante largos periodos (Santonja, 1992). La presencia de rodamientos diferentes en los materiales de Salmedina, así como el frecuente reaprovechamiento de materiales para su retalla, es prueba inequívoca de las visitas recurrentes que estos espacios han experimentado trascendiendo los propios límites del Paleolítico Antiguo. La acusada dispersión de materiales enmascara agrupaciones que mediante la aplicación utilizada, pueden ser entendidos. Parece concluyente que en las zonas donde abunda la materia prima los modelos de captación distorsionan el resultado arqueológico con respecto a las zonas donde escasean. Durante el Paleolítico Antiguo las estrategias llevadas a cabo, como venimos repitiendo, son de captación local y con un alto grado de inmediatez u oportunismo. Se observa una coincidencia de las fases de aprovisionamiento, transformación y consumo en espacios localizados, si bien la primera categoría aparece claramente sobredimensionada. Los elementos ajenos al medio son muy escasos, por lo que se puede hablar de que la movilidad en cuanto a la captación de materias primas, se ve reducida al paisaje inmediato a la actuación del grupo, y siendo quizás subsidiario del aprovechamiento de otro tipo de recursos, por ejemplo faunística.

Por todo ello, planteamos como hipótesis que existiendo tan amplia oferta de materia prima, los grupos paleolíticos deambularían de forma recurrente por estos espacio sucesivamente a lo largo de todo el Paleolítico (tanto como en etapas posteriores), pero que la naturaleza de los dife- rentes depósitos de materia prima, pudieron condicionar los modelos de explotación del medio de manera diferenciada tanto en el espacio (márgenes del río) como en el tiempo. Estas estrategias parecen acentuarse durante el Paleolítico Medio, momento en el que los requerimientos de materia prima de calidad se acentúan por razones de índole tecnológica.

\section{Bibliografía}

BAENA PREYSLER, J. (1992): "Talleres paleolíticos en el curso final del río Manzanares" Patrim. Arq. del Bajo Manzanares. U.A.M.

BAENA PREYSLER, J., CONDE, C., CARRIÓN, E., (1997): "Estrategias de captación durante el paleolítico antiguo en la región sur de Madrid", Rubricatum, 2, :69-76.

BAENA, J.; BLACO, C.; QUESADA, F. (1999): Los S.I.G. y el análisis espacial en Arqueología.

BAENA PREYSLER, J., CONDE, C., GAMAZO, M. SESÉ, C., SOTO, E., (2002) "Repertorio bibliográfico de yacimientos paleolíticos en el Manzanares y Jarama" Bifaces y Elefantes., Zona cero.

BAKER, C. (1978): "The size effect: an explanation of variability in surface artifact assemblage content". American Antiquity Vol. 43, 1º: 288-293.

BARANDIARÁN MAESTU, I. (1973): Excavaciones en la Cueva de los Casares (Riba de Saélices,Guadalajara). Madrid.

BERMÚDEZ DE CASTRO, J.M., CARBONELL, E \& ARSUAGA, J.L. (ED) (1999): Gran Dolina Site: TD6 Aurora Stratum (Burgos, Spain). J. of Human Evolution, 37: 309-700

CIUDAD SERRANO, A, ET.AL (1981): "Contribución a un mapa del Paleolítico Inferior y Medio en la provincia de Ciudad Real" Cuadernos de Prehistoria y Arqueología 78.Madrid.

COBO A.; GAMAZO, M.; HOYOS, M.; SOTO, E. (1979): "Los yacimientos Paleolíticos de las terrazas del Manzanares. Estado actual de la cuestión”. I Jornadas de estudios sobre la Provincia de Madrid. Dip. Prov. de Madrid.

COBO, A.; GAMAZO, M. (1983): "Desarrollo de las teorías sobre la edad y formación de las terrazas del Manzanares. Nuevas aportaciones". Homenaje a $M$. Almagro. Tomo I. Madrid.

CONDE, C. BAENA,. J. CARRIÓN, E. (2002): “.Los mode-

5 El estudio completo del yacimiento es fruto del trabajo de investigación para el tercer ciclo de Carmen Conde Ruiz, dirigido por el Dr. Javier Baena Preysler. 
los de explotación de los recursos líticos durante el Pleistoceno de la región de Madrid." Homenaje al profesor Vallespí. SPAL Revista de Prehistoria y Arqueología 9 2000. Universidad de Sevilla.

DÍEZ MARTÍN, F. (2000): El poblamiento paleolítico en los páramos del Duero. Serie STUDIA ARCHAEOLOGICA, $\mathrm{n}^{\circ} 90$. Universidad de Valladolid.

FERNANDEZ PERIS, J. (1998): "La Coca, (Aspe, Alicante) área de aprovisionamiento y talla del Paleolítico Medio" Recerques del Museu D' Alcoi, Alicante 7: 9-46.

GARCÍA SANJUÁN, L., (2005) Introducción al reconocimiento y análisis arqueológico del territorio. Ariel Prehistoria. Barcelona 357.

GAMAZO M., (1982) Prospecciones en las terrazas de la margen derecha del río Manzanares (Getafe, RivasVaciamadrid). Noticiario Arqueológico Hispánico. 14, Madrid.

GENESTE, J.M.(1988): "Systèmes d’aprovisionnement en materies premières au paléolithique moyen et au paléolithique supérieur en Aquitaine”. L'homme de Néandertal. Vol.8 : La Mutation. Lieja. :61-70.

GENESTE, J.M.(1991): "L’Aprovisionnement en matières premières dans les systèmes de production lithique: la dimension spatiale de la technologie." Cadenas Operativas Líticas. Treballs d'Arqueologia, $\mathrm{n}^{\circ} 1$. Barcelona. : 1-36.

GONZALEZ ORTIZ, J. (1978): "Notas sobre un yacimiento paleolítico de superficie localizado en el río Jabalón (Ciudad Real)" Archivo Prehistórico Levantino. XV

JIMÉNEZ GONZÁLEZ, M.C.; MARTÍN BENITO, J.I.; BENITO ALVAREZ, J.M. (1987): "El yacimiento Achelense del Rincón (San Muñoz Salamanca). Contribución al estudio de un yacimiento Achelense de superficie. Primera parte: Metodología. Estudio del grupo de bifaces." Studia Zamorensia Historica $\mathrm{n}^{\circ}$ VIII, ed. Unv. Salamanca: 151-188.

JIMÉNEZ MANZANARES, A.; MARTÍN BLANCO, P.; SANGUINO GONZÁLEZ, J.; GÓMEZ DE LA LAGUNA, A. J. (1995): "El gran abanico aluvial del Guadiana alto, reflexiones en torno al concepto de yacimiento". Zephyrus, XLVII:75-100.

KOLEN, J., ET.AL. (1999): "Middle Paleolithic surface scatters: How informative? A case of study from limburg (The Netherland)" ROEBROEKS, W.; GAMBLE, C. (Eds.): The Middle Paleolithic Occupation of Europe, 23-48. University of Leiden.

LÓPEZ RECIO, M.; BAENA, J.; VÁZQUEZ, J.; GÓNZALEZ, J.A.: (2000): "Captación de recursos líticos durante el Paleolítico Medio en la comarca de la Mancha Toledana: El cerro del Molino de san Cristóbal. (Camuñas)". II Congreso de Arqueología de la provincia de Toledo. La mancha Occidental y la Mesa de Ocaña. Diputación Provincial de Toledo: 13-27.

LÓPEZ RECIO, M.; ROMERO SALAS, H.; MANZANO ESPINOSA, I.; ESCALANTE GARCÍA, S., PÉREZ GONZÁLEZ, A.; BAENA PREYSLER, J.; CARRIÓN SANTAFÉ, E.; CONDE RUÍZ, C.; VELÁZQUEZ RAYÓN, R. (2005 E.P.) "Caracterización geoarqueológica de los depósitos sedimentarios del yacimiento de La Gavia (Cuenca del Río Manzanares, Madrid)". En Pérez González A. Santonja M. (Ed) Actas de la IV Reunión de Geoarqueología, Soria.

MÁRQUEZ TRIGUERO, E. (1965): "Sobre un nuevo yacimiento del Paleolítico en Coslada (Madrid)". Not. y comun. del Inst.Geológ. y Minero de España, 78. Madrid.

MARTÍN BLANCO, P.; JIMÉNEZ MANZANARES, A.; SANGUINO GONZÁLEZ, J.; GÓMEZ DE LA LAGUNA, A.J. (1994): "Identificación de cadenas operativas líticas en el sitio arqueológico de Casa de la Mina II (Argamisilla de Alba, C. Real). Consideraciones acerca de los yacimientos superficiales sin contexto estratigráfico", Zephyrus, XLVII, Salamanca :15-40.

MOURE ROMANILLO, A.; GARCÍA SOTO, E. (1983): «Cueva Millán y la Ermita: dos yacimientos musterienses en el Valle Medio del río Arlanza». Boletín del Seminario de Estudios de Arte y Arqueología, tomo XLIX. pp. 5-30.

OBERMAIER H. (1925): "El hombre fósil" Comisión de Investigaciones Paleontológicas y Prehistóricas seg. edición, 9

OBERMAIER , H.; WERNERT , P.; PÉREZ DE BARRADAS, J. (1921): "El Cuaternario de las canteras de Vallecas (Madrid)”. Bol. Inst. Geol. de España, XLII. Madrid.

PEREZ DE BARRADAS, J.(1919): "Nuevos yacimientos paleolíticos de superficie de la provincia de Madrid”. Bol. de Real Soc. Esp. de Historia Natural T.XIX. Madrid.

PÉREZ DE BARRADAS, J.; WERNERT, P. (1921A): "Yacimientos paleolíticos del Valle del Manzanares (Madrid)". Junta Sup. Exc. Antigüedades, Memoria 33. Madrid.

PÉREZ DE BARRADAS, J.; WERNERT, P. (1921B): "Excursión geológica por el valle inferior del Manzanares". Boletín Sociedad Ibérica de Ciencias Naturales, XX(III), 1-21.

PÉREZ DE BARRADAS, J. (1924): "Introducción al estudio de la prehistoria madrileña" Revista de Biblioteca, Archivo y Museos. Ayuntamiento de Madrid.

PÉREZ DE BARRADAS, J. (1926): "Estudios sobre el terreno cuaternario del valle del Manzanares, Madrid”. Ayuntamiento de Madrid. 
PÉREZ DE BARRADAS, J. (1929): "Los yacimientos prehistóricos de los alrededores de Madrid", Bol. Inst. Geol. y Minero, LI, 153-322.

PÉREZ GONZALEZ, A. (1975): Hoja y Memoria del 1:50.000 (nr.582). I.G.M.E. Madrid.

PÉREZ GONZALEZ, A.; CALVO SORANDO, J.P. (1989): Hoja y Memoria del 1:50.000 ( nr. 559) I.G.M.E. Madrid.

ROYO GOMEZ J. MENÉNDEZ L. (1929): "Mapa y memoria explicativa de la hoja nr.559, Madrid" Instituto Geológico y Minero Español.

SANTONJA, M. (1986): "Valgande (Puebla de Yeltes, Salamanca). Área de talla y sitio de ocupación del Paleolítico Medio". Numantia, II. pp. 33-87.

SANTONJA, M. (1992). La adaptación al medio en el Paleolítico Inferior de la Península Ibérica. Elementos para una reflexión, en Elefantes, ciervos y ovicaprinos. Economía y aprovechamiento del Medio en la Prehistoria de España y Portugal (A. Moure Romanillo, ed.), Santander, pp. 37-76.
SILVA, P.G. (2003) EL CUATERNARIO DEL VALLE INFERIOR DEL MANZANARES (CUENCA DE MADRID, ESPAÑA), Estudios Geol., 59: 107-131.

VALLESPI PEREZ E. (1976) Achelense y Musteriense de Porzuna.(Ciudad Real). Material en superficie (coleccion E.Oliver). Museo de Ciudad Real Colección, estudios y Monografías, 1.

VALLESPÍ PÉREZ, E. (1988): "Paleolítico Medio de aspecto Postachelense en la depresión inferior del Guadalquivir" Espacio, Tiempo y Forma. Serie 1 Prehistoria.

VALLESPÍ PÉREZ, E. (1989): "Paleolítico Medio indeterminado, de aspecto postachelense, en ámbitos fluviales del sur y centro de la Península Ibérica" Veleia 6.

VEGA, G. (1983): “ Los problemas del Paleolítico Medio en España”. Homenaje al Prof. Almagro Basch Tomo I, 15-129. 